\title{
Enhancement Effects of the STATCOM on the Distance Relay Protection
}

\author{
Ahmed Nasser Alsammak, PhD \\ Assistance Professor in University of Mosul \\ College of Engineering \\ Electrical Engineering Dept. \\ Mosul-Iraq
}

\author{
Sarmad Arkan Janderma \\ University of Mosul \\ College of Engineering \\ Electrical Engineering Dept. \\ Mosul-Iraq
}

\begin{abstract}
Distance relay characteristics built depending on the line impedance and faults impedance. The relay response to the fault in the normal condition but when a Static Synchronous Compensator (STATCOM) added to the grid the characteristic of relay must be change and the relay may not response to the faults. In this paper, a sample 9 buses IEEE system was investigated to show the distance relay response when STATCOM was added. MATLAB-PSAT was used to show the effect of STATCOM that location in the middle and end points of the transmission line. The results observing of different fault resistance and various locations on the characteristics of the relay.
\end{abstract}

\section{Keywords}

Distance Relay, STATCOM, MATLAB-PSAT.

\section{INTRODUCTION}

In the last years, the security and reliability of the electric power system has more significant. At the same time, the distance protection is one of these significant that require great attention, because it plays an important role in the protection systems, but it may be exposed during the work of some of the effects that may play a negative role in their performance, Therefore the researchers have been constantly improving the performance and development of the distance relay to detect faults and increase the speed of work as well as sensitivity and change the characteristics of the relay to suit the prevailing conditions of the system [1-3].

The use of Flexible AC Transmission System (FACTS) as a static synchronous compensator in the power transmission system to enhance the electric power transmission and optimize the power system has become important on a global scale in recent years. The FACTS systems, such as the STATCOM, have supported the transmission process in the power system while enhancing transmits power, improving power, controlling flow, and increasing voltage stability. In spite of its positive role in electrical systems in maintaining the voltage stability and power and as a result stability of the power system, as well as its low cost compared to the establishment of a new transmission line to enhance the power transfer and environmental impact which is virtually nonexistent but unfortunately the existence of FACTS devices in the fault path will affect the voltages and current values in the transient and steady state and as a result will affect the operation of the protection systems. [4-5].

Upon a time, many attempts had been made to show the effects some change on the distance relay.

S. Jamali, and et al [6] studied the effect of the STATCOM on the characteristics of the distance relay and found that the effect of the compensator is negatively reflected on the performance of the relay, where causes under and overreach to the distance relay. Also, the effect of the equivalent circuit was studied for the compensator, it was first considered as a voltage source and found the difference between the real value of the impedance and the apparent value was high. In the case of being considered an ideal current source, the difference was small. Ahmed Albehadili [7] studied the performance of the distance relay in compensated transmission lines by FACTS devices that Connected in parallel as the static synchronous compensator (STATCOM), The MATLAB was used to determine the type and location of the faults by constructing a logical circuit to determine the type of fault, where found that the fault site for the compensator and the operating modes of the compensator may cause problems such as over-reach and under-reach operations.

X.Y Zhou and et al. [8] presented the studying of the effect of STATCOM on the distance relay of a parallel-line power system by analysing the power frequency. They found that the apparent impedance seen by the relay in the presence of a single-line to ground fault affected by the reactive power injected by the STATCOM which may lead to a situation either over reach or under reach of the distance relay.

A. Alsammak, and I. Abdul hammed [9] show performance improvement for distance relay based fuzzy logic for all prospective faults. In this paper, the effect of the STATCOM on the distance relay showed on IEEE 9 buses sample system. The results, explain how avoid the under-reach and over-reach by changing the relay characteristic.

\section{DISTANCE RELAY PROTECTION- STATCOM}

\subsection{DISTANCE RELAY PROTECTION}

Distance relay protection in simplest form is a system of protection and unity. The main goal of the distance relay is to protect the transmission lines and thus ensure the safety of the equipment in the power system such as generators; transformers etc. were called the distance relay because the principle of its work depends on the distance between the relay site and the point of fault [10].

The basic principle of the distance relay depends on the local measurements of the voltages and the current at the relay position, through which the line impedance is calculated continuously throughout the working period. If the measured impedance is less than the line impedance in the natural state, the relay will give a signal to the circuit breaker tell him the existence of a fault and ordered him to separate the part of the disruption of the proper part of the system If the measured impedance is equal to or greater than the impedance of the line, then the relay does not produce a trip signal. This condition expresses the normal state of work in the electric power system [11]. 


\subsection{STATIC SYNCHRONOUS COMPENSATOR (STATCOM)}

The STATCOM is a parallel device of the FACTS family of devices. Self-commutated devices such as the IGBT can be used to control all variables in the system including voltage and reactive power. The integration of FACTS devices increases transport flexibility and makes it economically viable. This helps to improve the power transfer because it provides a quick way to dampen oscillations in power system and also responds to sudden changes in loads, and support load during cutting in transmission lines or distribution lines and corrects voltages loads for quick control of reactive power and finally allow generators to work balanced with load in the system [12].

The single-line diagram of Reactive Power Generation by a Voltage Sourced Switching Converter shown in Fig.1. The charged capacitor CS supply a DC input voltage source to the converter to produce a controllable three-phase voltages with the frequency that inject to the AC power system. The generation voltage in-phase with, and coupled to the AC system voltage via a small reactance value [9]. When the produced output voltages changed, the reactive power will be change between the converter and the AC system that can be controlled as field control of synchronous machine. The working can be summarized in the points:

1. When the value of output voltage (amplitude) above the voltage of the power system, then the current will be go via the reactance to the power system and the converter will generate reactive power $(+Q)$.

2. When the output voltage under the voltage of power system, then the current will go from the power system to the converter and the converter will be consumption reactive power $(-\mathrm{Q})$.

3. When the output voltage is equal to power system voltage, so no supply or absorb any reactive power i.e. $\mathrm{Q}=$ zero, as shown in equation (1) [13].

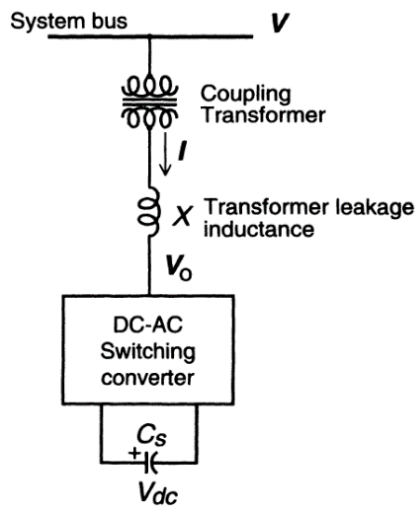

Fig. 1: Reactive Power Generation by a Voltage Sourced Switching Converter.

$\mathrm{Q}=\frac{V\left(V-V_{0}\right)}{X}$

Where:

Q: The supply or absorb reactive power.

$\mathrm{V}$ : voltage of power system (STATCOM Bus).

$V_{0}$ : The output voltage as amplitude.
The mid-point of a transmission line that connecting two systems is a good location for STATCOM because the voltage drop is the largest at this point. While a STATCOM connected at the load-end in a radial feed [5]. These are two situations were taken into consideration in this paper.

\section{SYSTEM MODEL}

The system was modelled in a three parts:

Part I: Modeling a standard electric power system consisting of 9-Busbar using MATLAB/PSAT for four cases:

First case; the system without a static compensator (STATCOM) and the absence of a fault (Normal Condition). as shown in Figure 2. The load flow studies will perform to determine pre-fault and faults conditions (Voltage, Currents) in the system using Newton-Raphson method.

Second case; find the best location (the weakest bus) of the STATCOM in the power system.

In order to identify the weakest bus in the system, the V-Q Sensitivity Method was used where the weakest bus that has the highest participation factor to the smallest eigen-value. After analysing using MATLAB / PSAT, resulting in, Bus No. five is the weakest bus and centred of the weakest area, as shown in Figure 3. and Figure 4.

Third case; connect the static compensator depend on second case at mid-point and end-point of the transmission line (7-5) within the power system and the absence of the fault condition (Normal Condition), as shown in Figure 5a. and Figure 5b.

As a result, the STATCOM was connected at bus 5 (weakest bus) as shown in Figure 5a and Figure 5b.,

Fourth case; apply a three phase to ground fault on the first and second cases that provides the possibility of controlling the value of the fault resistance (Rf). In order to represent the faults on different locations, the technique shown in Fig.6

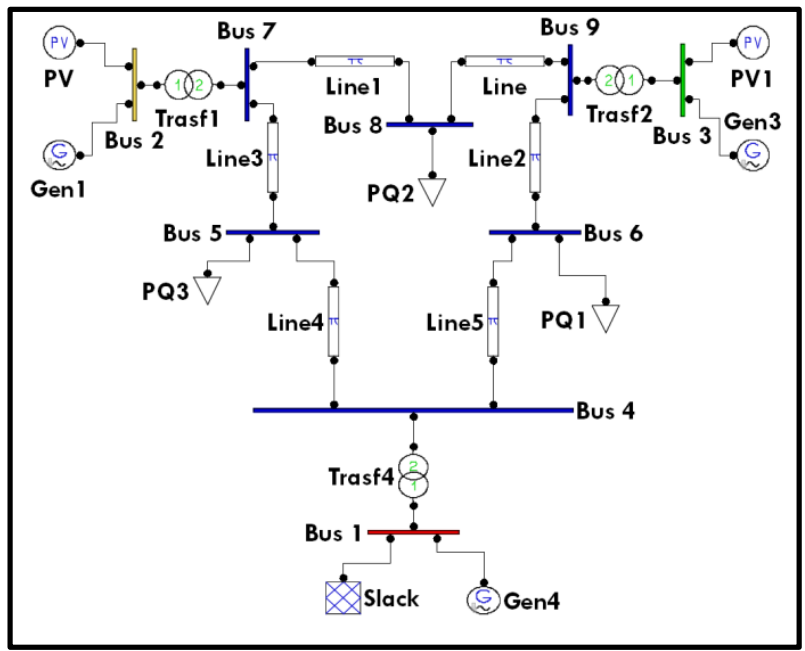

Fig 2: (IEEE-9bus) Power System Representation using MATLAB / PSAT. 


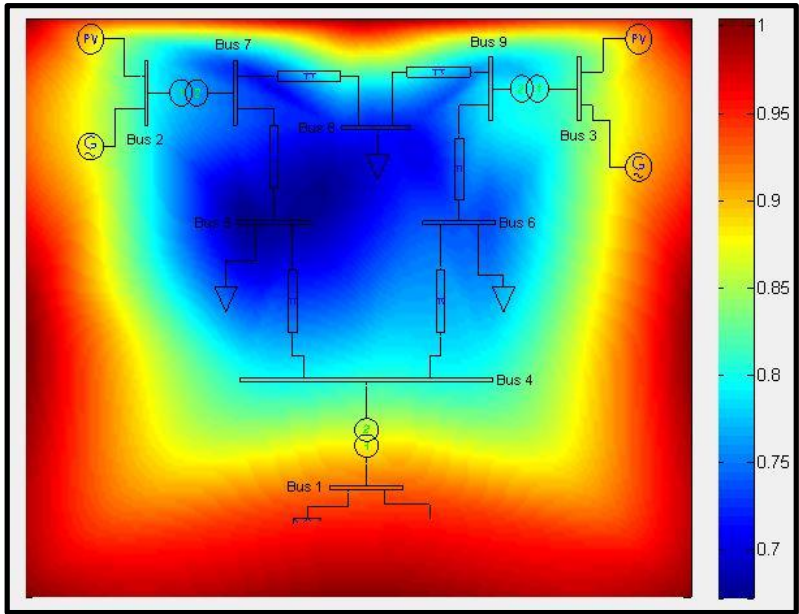

Fig 3: The weakest bus in the power system in the 2-D view.

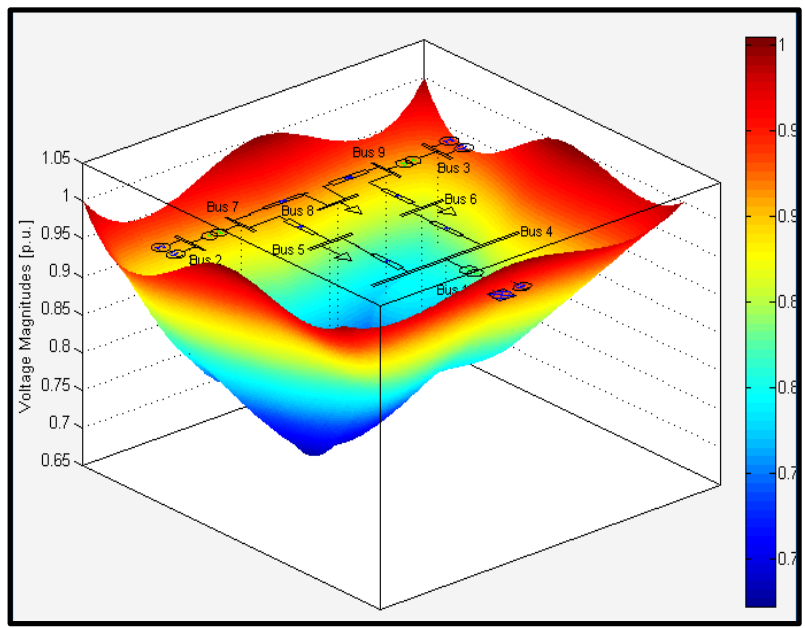

Fig 4: The weakest bus in the power system in the 3-D view.

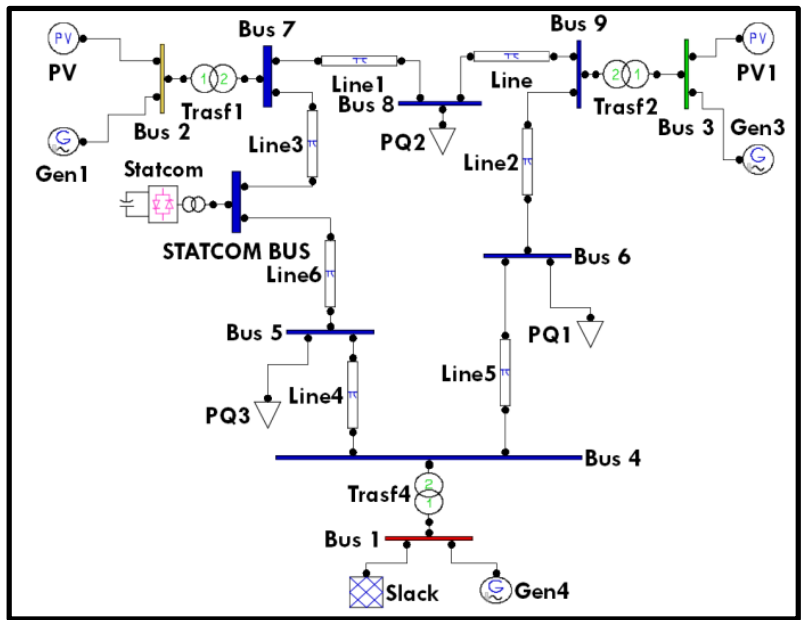

Fig 5a: (IEEE-9bus) Power system with STATCOM at Midpoint representation using MATLAB / PSAT.

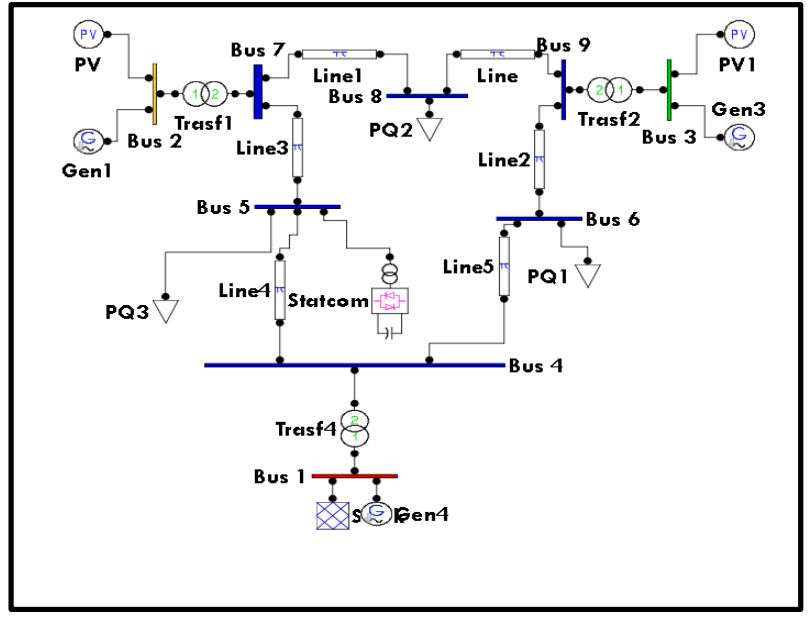

Fig 5b: power system with STATCOM at End point.

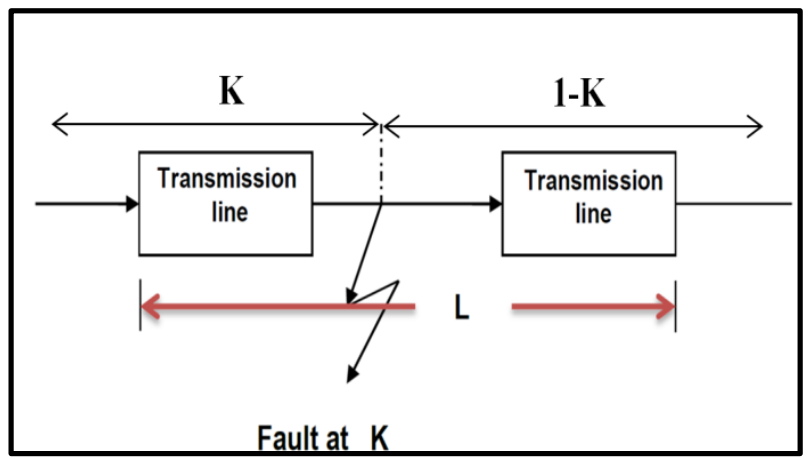

Fig 6: The faults on different locations technique.

Part II: MATLAB-Simulink model for the distance impedance calculation.

Figure 7, shows a Matlab model for the distance impedance involves the values of both the line resistance and the reactance. The fault impedance locus is plotted without use the STATCOM for the variable fault resistance. It also includes introducing the STATCOM with the same values of the fault resistance to find the effect of compensation on the system.

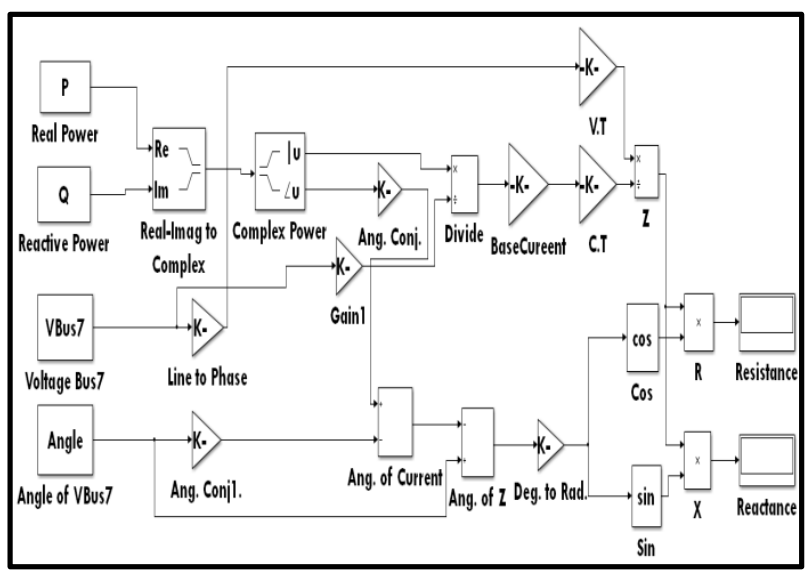

Fig 7: Matlab-Simulink model for the line impedance calculation. 


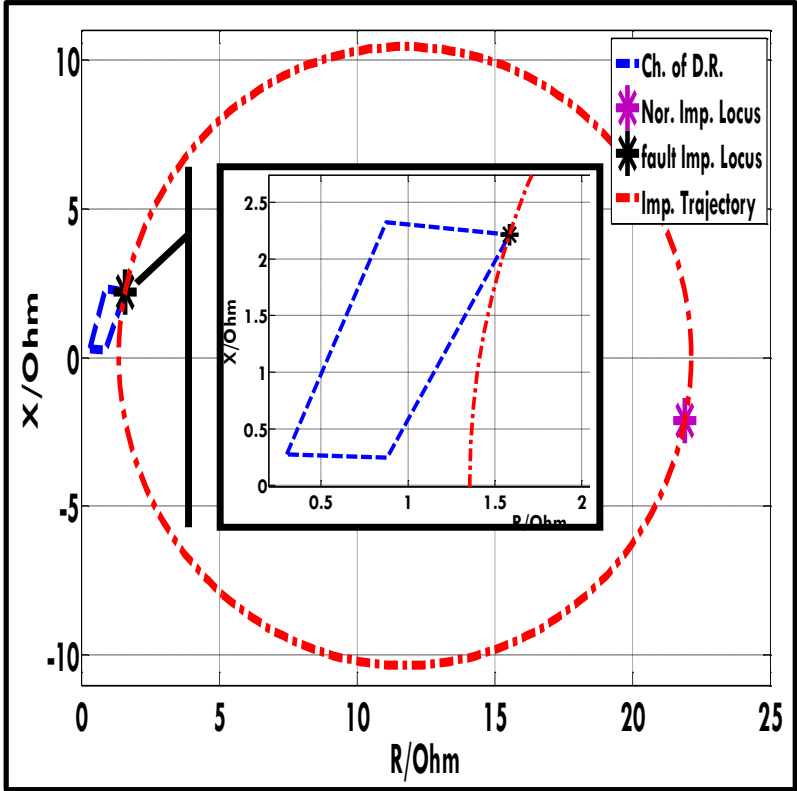

Fig 8: The impedance locus in the case of the absence of the STATCOM.

\section{SIMULATION RESULTS}

The value of the phase current and the phase voltage at the location of distance relay (Bus7) in the absence of the STATCOM in the system are shown in Table 1.

Table 1. Phase values of the voltage and the current at the location of distance relay at the Bus7

\begin{tabular}{|c|c|}
\hline V Relay [kV] & 136 \\
\hline I Relay [A] & 123 \\
\hline
\end{tabular}

The transformer ratio can be calculated depend on Table 1 as shown in Table 2.

Table 2. Voltage and current transformers

\begin{tabular}{|l|c|}
\hline Voltage Transformer Ratio (V.T) & $136 / 110$ \\
\hline Current Transformer Ratio (C.T) & $5 / 123$ \\
\hline
\end{tabular}

After selecting the values of each transformer ratios, the distance variable three-phase to ground fault, with variable fault resistance, was applied to the system. The impedance locus of the system for three cases is drawn. The first case without used STATCOM, as shown in Figure 8. As it is clear from the Figure 9 that the impedance trajectory falls within the characteristics of the work of distance relay thus the relay will give a trip signal that it does not suffer from any defect. But in the presence of the static compensator, signal as it will suffer from under-reach. As shown in Figure 9. and Figure 10.

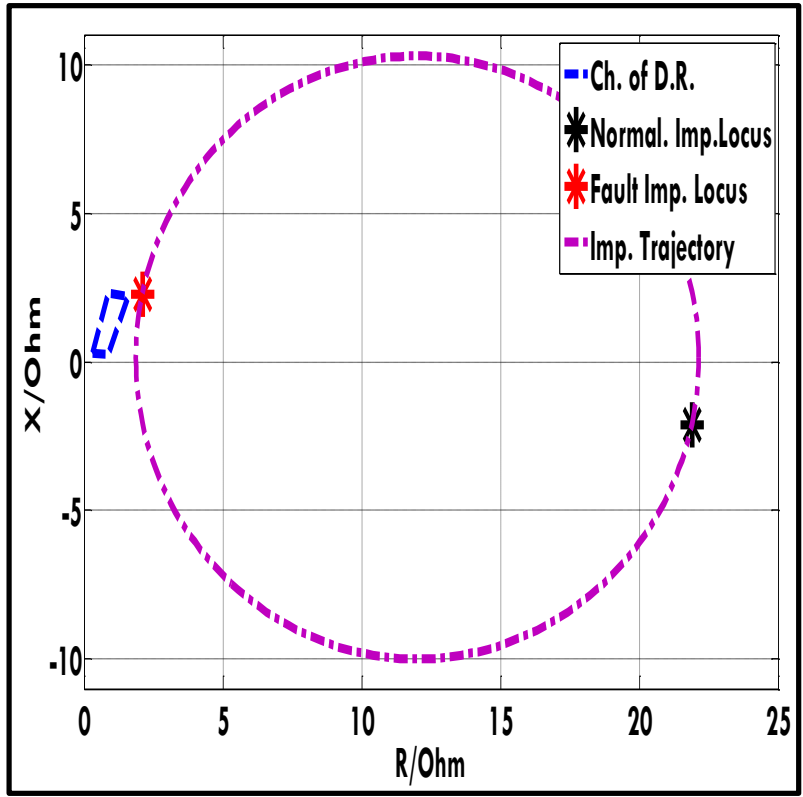

Fig 9: The impedance locus in the case of the presence of the STATCOM at mid-point.

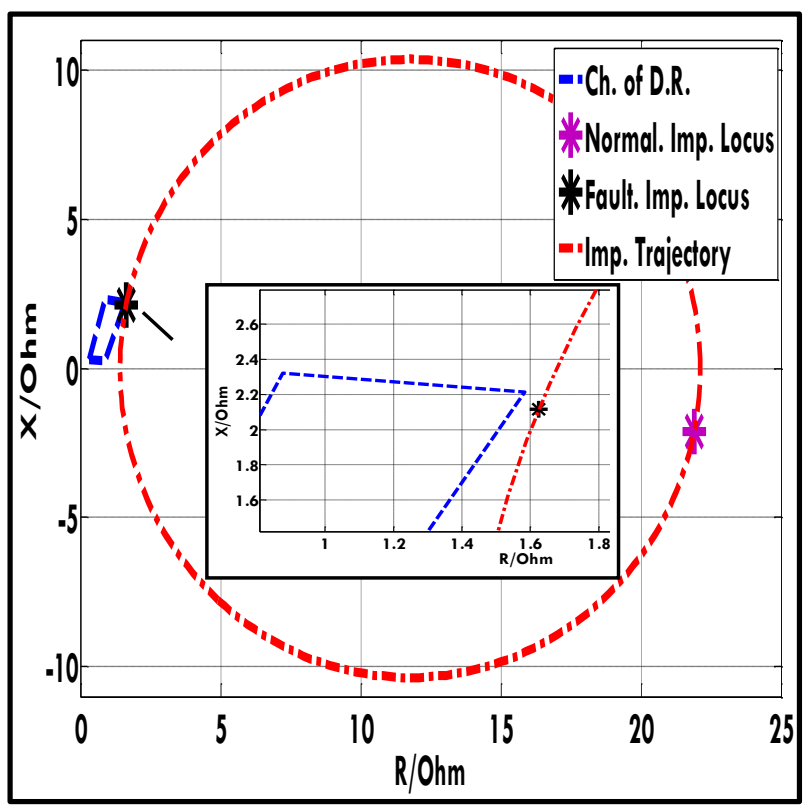

Fig 10: The impedance locus in the case of the presence of the STATCOM at end-point.

Data sets were collected after observing using the STATCOM on the distance relay response, where it causes an under-reach state. These data was used to build a fuzzy logic the working as distance relay shown in Fig. 11. The fuzzy action shows an overcome the under-reach and the adopted distance relay work correctly if there is a STATCOM in the system. 


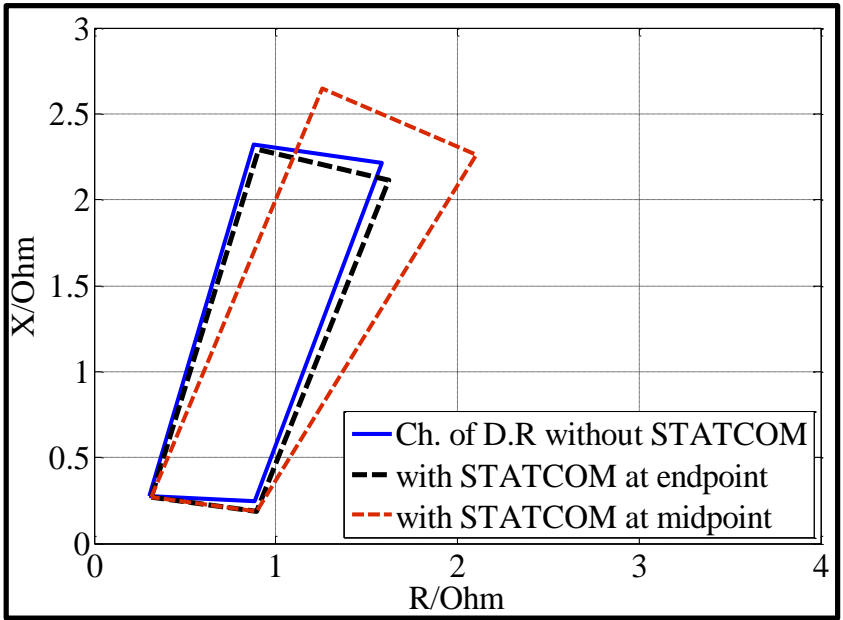

Fig 11: Characteristics of work adapted by fuzzy logic.

\section{CONCLUSION}

This paper investigated the effects of use STATCOM in the IEEE-9 Bus power system on a distance relay characteristics. The conclusion can be summarized as the following:

1 The compensation of the STATCOM depends on:

1.1 Increase fault resistance the compensation degree will be increase, while reducing fault resistance gives reduce the compensation degree.

1.2 Increasing the location of fault (K) the compensation degree will increase and the fault current will be determined by the high line impedance.

2 The STATCOM was used to improve the stability of the power system [midpoint or endpoint] of the transmission line. Any transmission line must protect via distance protection that depend on measurement of fault impedance. The characteristics of distance relay will affect by STATCOM and then the relay suffers from under-reach situation, but in different rates depends on position of STATCOM.

3 When there is a STATCOM located in the mid-point of a transmission line protected by a distance relay that will have the greatest effect on the working characteristics of the distance relay, it will result in the case of underreach and the greatest effect occurs when the fault site $(1>\mathrm{k}>0.5)$ from the line.

4 When a STATCOM is present at the end-point of a transmission line that protected by a distance relay it will have a slight effect on working characteristics of the distance relay compared to its presence in the midpoint of the transmission line, because the STATCOM will be out of the fault path ,It will also cause under- reach but only a small percentage compared to the under -reach condition when it is in the midpoint of the-line.

\section{REFERENCES}

[1] P. M. Anderson, "power system protection", McGraw Hill, p.p. 413-414, 1998

[2] Nan Zhang, "Advanced fault diagnosis techniques and their role in preventing cascading block outs", $\mathrm{PhD}$ thesis, Texas A\&M University, Dec.2006.

[3] Gorakshanath B. Abande, MFAR Satarkar, Maroofa H. Rawoot," Impact of STATCOM on Distance Relay", International Conference on Circuit, Power and Computing Technologies [ICCPCT], 2014.

[4] A. G. Phadke, M. Ibrahim and T. Hlibka,"Fundamental basis for distance relaying with symmetrical components", IEEE Transactions on Power Apparatus and Systems , vol. 96, no. 2, pp. 635-646, 1977.

[5] D. L. Waikar, S. Elangovan and A. C. Liew, , "Fault impedance estimation algorithm for digital distance relaying," Jul 1994 in IEEE Transactions on Power Delivery, vol. 9, no. 3, pp. 1375-1383,

[6] S. Jamali, et al, "Measured impedance by distance relay for inter phase faults in presence of STATCOM," in Power and Energy Society .General Meeting-Conversion and Delivery of Electrical Energy in the 21st Century, EEE, 2008, pp. 1-6.

[7] Ahmed Albehadili, Ikhlas Abdul-Qader,"Analysis of distance relay performance on shunt FACTScompensated transmission lines", IEEE International Conference on Electro/Information Technology (EIT), 2015.

[8] X.Y Zhou, H.F Wang, R.K Aggarwal, P.Beaumont ,"The impact of STATCOM on distance relay", 15th PSCC, Liege, Session 19, Paper 4,2005.

[9] Ahmed Nasser Alsammak, and Ibrahim Ismael abdul hameed, "Performance improvement for distance relay based fuzzy logic for all prospective faults", IRJET, Volume (05), Issue (08), Aug 2018.

[10] B. Ram, D. Vishwakarma,"Power System Protection \& Switchgear", pp. 3-6, McGraw-Hill Pub. Co. Ltd., New Delhi, 1995.

[11] S.M. Brahma, "Fault Location Scheme for a Multi Terminal Transmission Line Using Synch. Voltage Measurements", IEEE Transactions on Power Delivery, Vol. 20, No. 2, pp. 1325-1331, April 2005.

[12] R. Mohan Mathur, and Rajiv K. Varma. Thyristor-Based FACTS Controllers for Electrical Transmission Systems. John Wiley \& Sons, Inc. publication, 2002.

[13] A. Arulampalam, J. B. Ekanayake, and N. Jenkins, "Application study of a STATCOM with energy storage", Generation, Transmission and Distribution, IEE Proceedings, Vol.150, No.3, pp.373-384, 13 May 2003. 